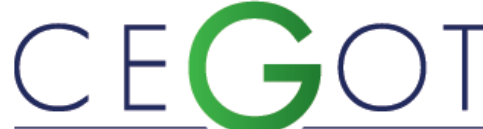

Centro de Estudos de Geografia e Ordenamento do Território
Instituto de Arquitectura y Urbanismo, Universidad Nacional de

San Martín

B1644CTI, Buenos Aires, Argentina. Lavalle 2729, San Fernando

apotocko@gmail.com

\title{
Transformaciones de un territorio fluvial. Urbanización y regulación hídrica del río Reconquista (Buenos Aires, Argentina)
}

Transformações de um território fluvial. Urbanização e regulação da água do rio Reconquista (Buenos Aires, Argentina)

Transformations of a river territory. Urbanization and water regulation of the Reconquista river (Buenos Aires, Argentina)

Referência: Potocko, Alejandra (2018). Transformaciones de un territorio fluvial. Urbanización y regulación hídrica del río Reconquista (Buenos Aires, Argentina). Revista de Geografia e Ordenamento do Território (GOT), n. ${ }^{\circ} 14$ (setembro). Centro de Estudos de Geografia e Ordenamento do Território, p. 283-305, dx.doi.org/10.17127/got/2018.14.012

\section{RESUMEN}

El Reconquista es uno de los tres grandes ríos que atraviesan la Región Metropolitana de Buenos Aires. Es un típico río de llanura cuyas condiciones naturales no fueron siempre consideradas en la ocupación del suelo y en particular, en la expansión metropolitana de Buenos Aires que se produjo desde mediados del siglo XX. Como consecuencia, los desbordes naturales del río afectaron a un número creciente de población asentada en el valle de inundación a pesar de que, desde la década de 1970, grandes obras de ingeniería hidráulica intentaron reducir el riesgo de inundaciones. A partir de considerar las relaciones entre la urbanización y las soluciones técnicas frente a las inundaciones, es posible identificar tres momentos de las transformaciones del territorio fluvial del Reconquista: el de la retención del agua en las nacientes, el del desagüe rápido y el de la regulación hídrica integral.

Palabras clave: Río Reconquista, Región Metropolitana de Buenos Aires, transformaciones territoriales, urbanización, obras hidráulicas, cartografías interpretativas.

\section{RESUMO}

O Reconquista é um dos três grandes rios que atravessam a Região Metropolitana de Buenos Aires. É um rio típico de planície, cujas condições naturais nem sempre foram consideradas no uso da terra e, em particular, na expansão metropolitana de Buenos Aires que ocorreu desde meados do século XX. Como consequência, os transbordamentos naturais do rio afetaram um número cada vez maior de população instalada no vale de inundação, apesar de que, desde a década de 1970, grandes trabalhos de engenharia hidráulica tentaram reduzir o risco de inundações. Ao considerar as relações entre urbanização e soluções técnicas para inundações, é possível identificar três momentos nas 
transformações do território fluvial do Reconquista: o momento da retenção de água nas nascentes, o momento da drenagem rápida e o momento da regulação hídrica integral.

Palavras-chave: Rio Reconquista, Região Metropolitana de Buenos Aires, transformações territoriais, urbanização, obras hidráulicas, cartografia interpretativa.

\section{ABSTRACT}

Reconquista is one of the three great rivers that cross the Metropolitan Region of Buenos Aires. It is a typical plain river whose natural conditions were not always considered in land occupation and in particular, in the metropolitan expansion of Buenos Aires that occurred since the mid-twentieth century. As a consequence, the natural overflows of the river affected an increasing number of population settled in the flood valley despite the fact that, since the 1970s, major hydraulic engineering works attempted to reduce the risk of flooding. Considering the relationships between urbanization and technical solutions against flooding, it is possible to identify three moments in the transformations of the Reconquista fluvial territory: the one of water retention in the springs, the one of rapid drainage and the one of the integral hydric regulation.

Keywords: Reconquista river, Buenos Aires Metropolitan Region, territorial transformations, urbanization, hydraulic works, interpretative cartography.

\section{Introducción}

El Reconquista es uno de los tres grandes ríos que atraviesan la Región Metropolitana de Buenos Aires (RMBA) ${ }^{1}$ (Figura 1). Recorre aproximadamente $50 \mathrm{~km}$ en sentido sudoestenoreste desde sus nacientes en tierras rurales, atraviesa áreas de variados usos y densidades de ocupación, y en un entorno netamente urbano desemboca en el río Luján, tributario directo del río de La Plata. Eje estructurador de la cuenca hídrica que lleva su nombre, donde viven casi tres millones de personas, ${ }^{2}$ está gravemente afectado por recurrentes inundaciones y su creciente contaminación, lo cual no sólo perjudica al ecosistema natural, sino que también pone en riesgo a la población, en particular a aquella asentada sobre sus márgenes y el valle de inundación, que concentra a los sectores de extrema pobreza (Curutchet, Grinberg y Gutiérrez 2012).

\footnotetext{
${ }^{1}$ Compuesta por la Ciudad de Buenos Aires y cuarenta municipios de la Provincia de Buenos Aires.

2 Según datos del Censo Nacional de Población, Hogares y Viviendas realizado en 2010 por el Instituto Nacional de Estadística y Censos (Instituto Nacional de Estadística y Censos 2013).
} 


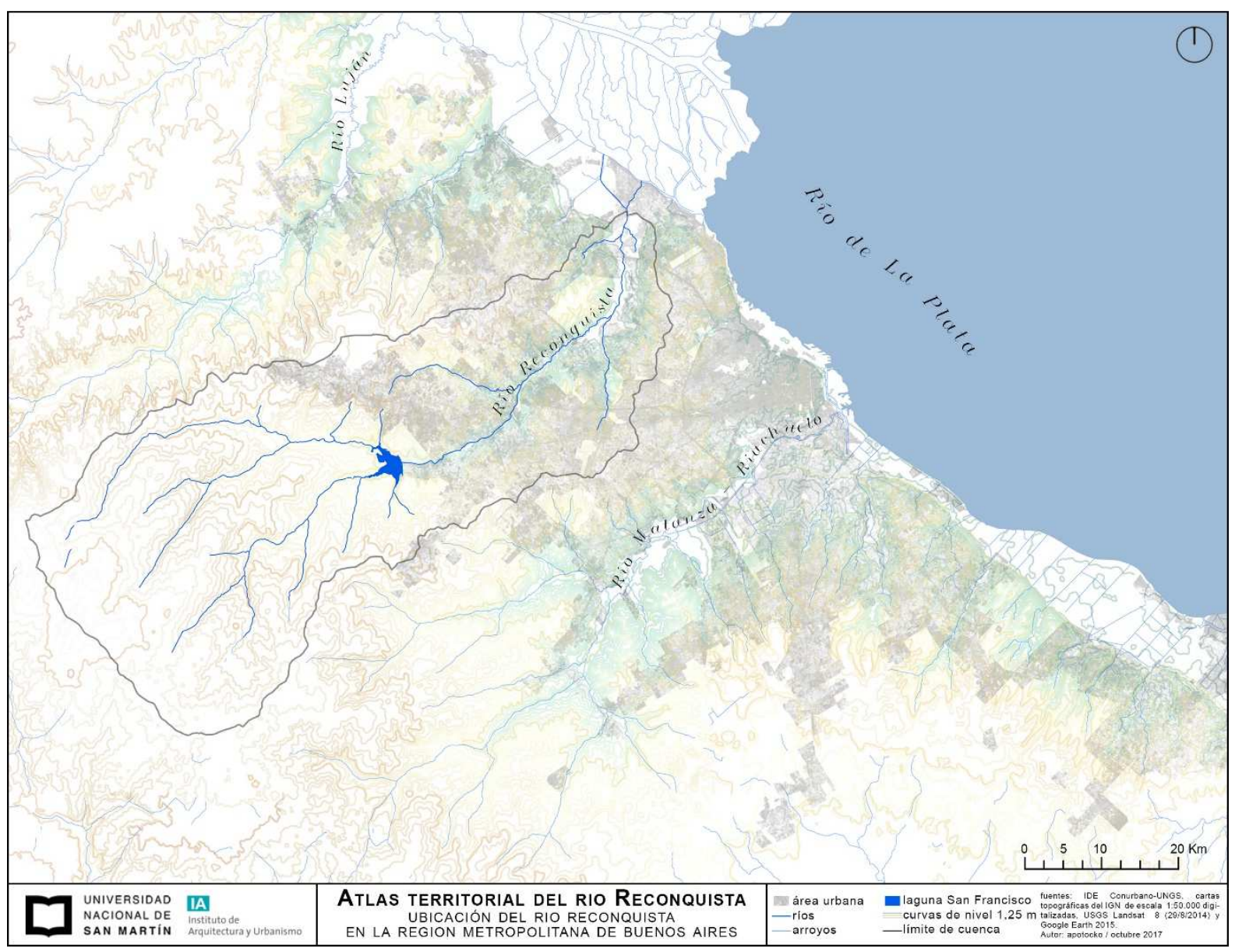

Figura 1 - Ubicación del río Reconquista en el Área Metropolitana de Buenos Aires. Fuente: Elaboración propia.

En su configuración natural, el río Reconquista es un típico río de llanura que presenta una pendiente baja y el fondo del cauce plano (Figura 2). El tramo superior o "Ilanura alta" se desarrolla desde las nacientes de los tributarios en tierras de aproximadamente +30 m.s.n.m. ${ }^{3}$, donde las vaguadas independientes aíslan bañados, hasta la zona de confluencia del río con el arroyo La Horqueta, donde el valle se estrecha. Un tramo medio se extiende desde aquel punto hasta la confluencia del arroyo Morón, donde el valle de inundación comienza a ensancharse. El tramo inferior, finalmente, se delimita desde aquel punto hasta su desembocadura y la integración con la cuenca baja del río Luján, donde presenta un amplio valle deprimido entre barrancas alejadas (cota inferior a $3 \mathrm{~m} \mathrm{I.G.N.).} \mathrm{Es} \mathrm{en} \mathrm{los} \mathrm{valles}$ medio e inferior, actualmente muy antropizados, donde el río corría meandroso,

\footnotetext{
${ }^{3}$ Calculado de acuerdo a las cartas topográficas del Instituto Geográfico Nacional (levantamientos topográficos de principios del siglo XX). En adelante se utilizarán las siglas I.G.N. para referenciar las elevaciones que surgen de analizar dichas cartas.
} 
conformando un territorio de bañados, lagunas temporales, riachos y arroyos intermitentes que aparecían y desaparecían con cada crecida de las aguas.

Tales condiciones no fueron siempre consideradas en la ocupación del suelo y en particular, en la expansión metropolitana de Buenos Aires que se produjo desde mediados del siglo XX. Como consecuencia, los desbordes naturales del río -potenciados en el tramo inferior por la sudestada4- afectaron a un número creciente de población asentada en el valle de inundación.

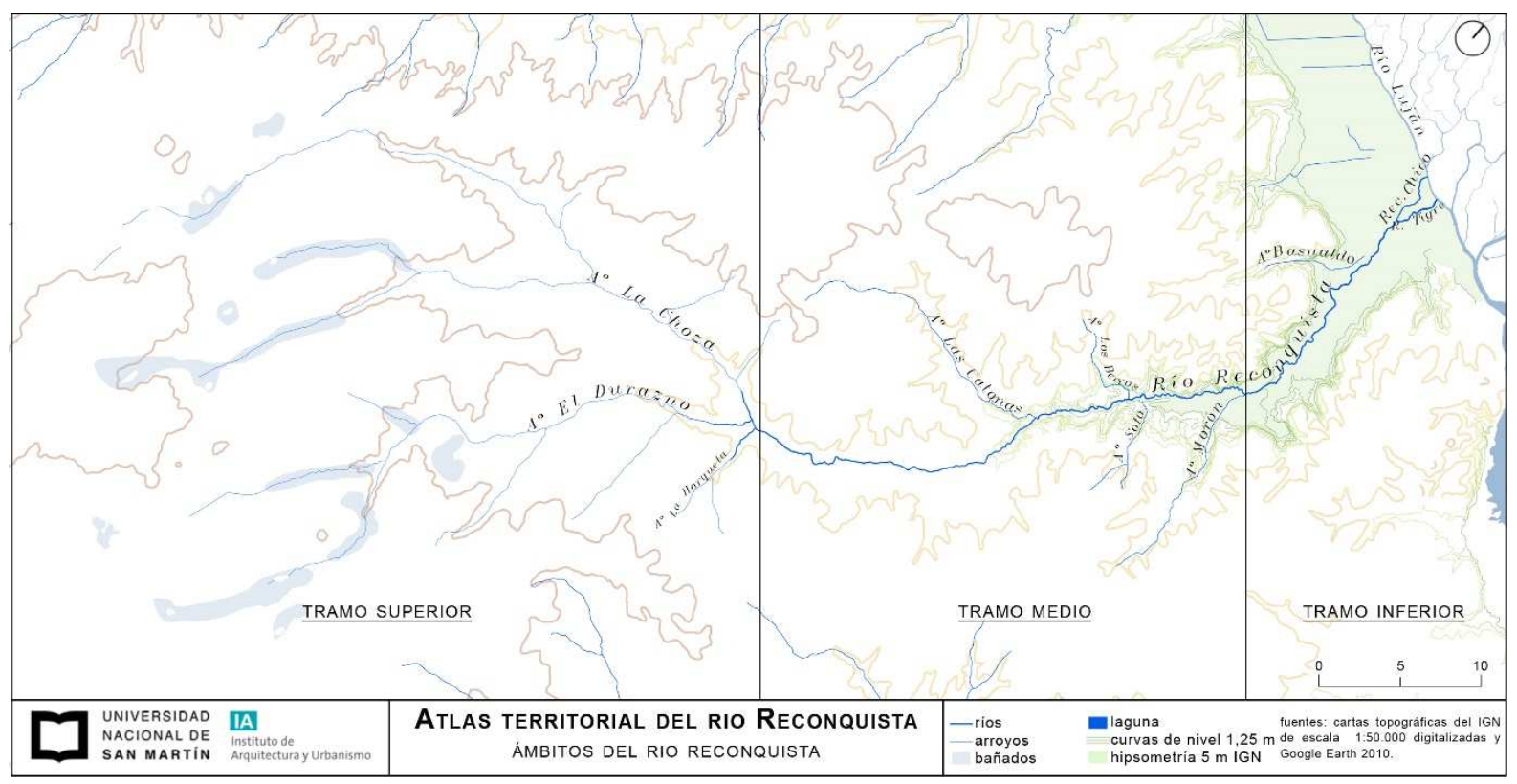

Figura 2 - Dibujo aproximado de la configuración natural del río Reconquista previo a la primera expansión metropolitana de Buenos Aires. Fuente: Elaboración propia.

En ese contexto, desde la década de 1970 grandes obras de ingeniería hidráulica transformaron el curso del río. Primero, la construcción de la represa Roggero; luego, la desviación del río por un curso artificial llamado Canal Aliviador; y finalmente, la ejecución del Programa de Control de Inundaciones y Saneamiento Ambiental desde mediados de la década de 1990; intentaron tanto retener el agua, para ralentizar su afluencia sobre las tierras más bajas en épocas de crecida, como desagotarla rápidamente, a fin de reducir el anegamiento de tierras bajas con aguas contaminadas; en una sumatoria de soluciones técnicas pensadas para el largo plazo y acciones coyunturales que fueron construyendo este territorio en el tiempo.

\footnotetext{
${ }^{4}$ Fenómeno meteorológico local de vientos de dirección sudeste que dificulta el escurrimiento normal de los cauces menores hacia el Río de La Plata.
} 
A partir de esas consideraciones, nos propusimos estudiar las relaciones entre la urbanización y las grandes obras de infraestructura hidráulica que desde la década de 1970 hasta mediados de la de 2000 buscaron reducir el riesgo de inundaciones y, en gran medida, dieron forma a su configuración actual (Figura 3)..$^{5}$ Según planteamos, las transformaciones del territorio fluvial del Reconquista -el que incluye el propio curso de agua y también el área más extensa que éste inunda (Williams 2017)- son producto de una construcción histórica que remite al mismo tiempo a la urbanización y a las soluciones técnicas pensadas para reducir el riesgo de inundaciones en cada momento dado.

Metodologicamente, se trató de analizar articuladamente tres ejes. Primero, examinamos la forma del río y sus tributarios en una secuencia de dibujos que realizamos en cuatro cortes temporales: 1939, 1972, 1985 y 2010. Segundo, miramos el río y sus transformaciones en relación al avance de la urbanización sobre el territorio, que examinamos en una serie de cartografías intencionadas de variadas escalas que informan sobre las áreas ocupadas en diferentes momentos (década de 1950, 1985 y 1997). La producción cartográfica responde al interés por generar lecturas intencionadas del territorio que, al considerar diferentes fuentes, escalas y temporalidades, son capaces de plantear nuevas hipótesis y preguntas de investigación sobre las relaciones entre procesos que se expresan territorialmente. ${ }^{6}$ Tercero, analizamos los documentos de las grandes obras de regulación hídrica ejecutadas en el Reconquista: el "Estudio Hidrológico del Río Reconquista" (Ministerio de Obras Públicas de la Provincia de Buenos Aires 1964), el informe "Cuenca Inundable Río Reconquista. Datos básicos" (Ministerio de Economía de la Provincia de Buenos Aires 1985) y la letra del Programa de Saneamiento y Control de las Inundaciones de la cuenca del río Reconquista (Dalairac 1997).

\footnotetext{
${ }^{5}$ El trabajo se enmarca en un Atlas territorial comprensivo de la cuenca Reconquista que estamos desarrollando en el Instituto de Arquitectura y Urbanismo de la Universidad Nacional de San Martín (Argentina), como una forma de describir el territorio y problematizarlo, y como un punto de partida para pensar en las alternativas de su transformación. Para mayores referencias ver Williams, Garay y Potocko (2017).

${ }^{6}$ En Potocko (2017) realizamos una primera puesta a punto de los materiales y métodos desarrollados en este trabajo.
} 


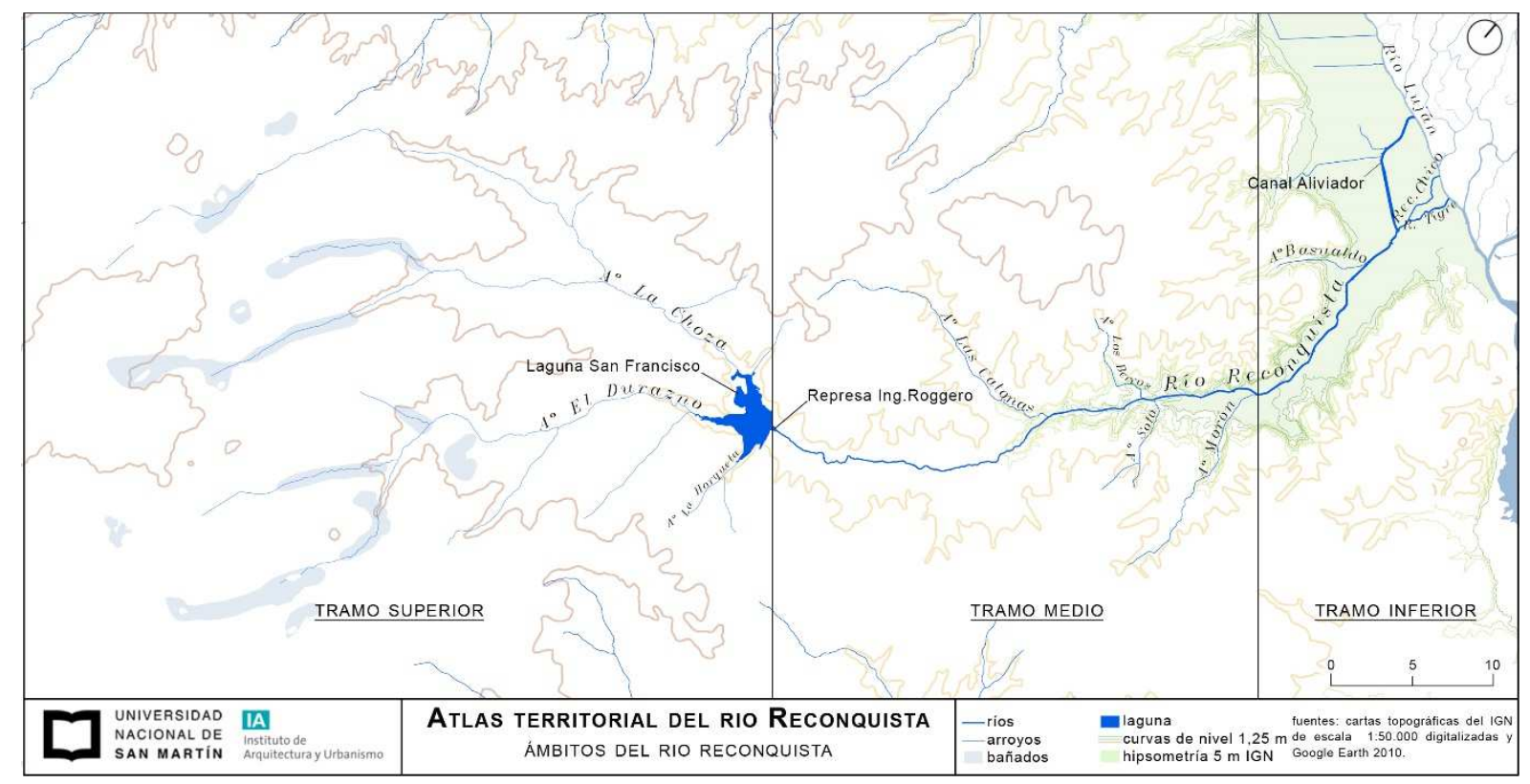

Figura 3 - Configuración actual del río Reconquista. Fuente: Elaboración propia.

Una amplia gama de trabajos analizaron las relaciones entre la urbanización y el río, en particular en torno a su valle de inundación. Por un lado, se encuentran aquellos que estudiaron cómo el agua y el suelo fueron afectados por la creciente urbanización, principalmente en relación a la contaminación ambiental (Alsina y Herrero 2000; Castañé et al. 1998; De la Torre, Ferrari y Salibián 2000; Federovisky 1988; Fernández y Herrero 2012; Kuczynski 1993; Salibián 2006); y por otro, los que mediante estudios de caso examinaron las lógicas contrapuestas de los actores que ocupan esas tierras (Cravino, Fournier, Neufeld y Soldano 2002; Curutchet, Grinberg y Gutiérrez 2012; D’hers 2013; Pintos 2012; Pugliese y Sgroi 2012; Ríos 2010; Santillán 2008; Segura 2006).

En contraste, la ejecución de politicas públicas hidráulicas y su articulación con la urbanización del territorio fueron menos estudiadas. Desde la ecología urbana, Sadañiowski (2003) abordó el problema de la ocupación de las tierras bajas del Reconquista, de las inundaciones del río y la construcción de la represa Roggero como solución a las mismas. Desde la geografía, Ríos (2010) analizó los procesos de urbanización de áreas inundables en el tramo inferior de la cuenca y la producción de espacios de riesgo de desastres dando cuenta de los efectos de las técnicas hidráulicas. Desde los estudios urbanos, Peralta (2017) examinó el desarrollo de un barrio popular en el borde del Reconqista en tierras que surgieron a partir de la rectificación del cauce del río; mientras Catenazzi, Cardozo, Peralta y Cañellas (2017) analizaron las relaciones entre ciudad y río en el borde del Reconquista 
durante los últimos 40 años focalizando en las transformaciones territoriales y los instrumentos de planificación desarrollados por los gobiernos locales.

Complementando esas miradas, nuestro enfoque intenta reconstruir una historia de largo aliento de la urbanización de la cuenca Reconquista y de las obras hidráulicas desde una escala regional, a través de una metodología que pondera las cartografías interpretativas del territorio. Desde esa clave, intentaremos iluminar algunas de las aristas de los procesos de construcción del espacio metropolitano desde mediados del siglo XX como insumo para la intervención en el territorio. Para ello, proponemos tres momentos interpretativos de las transformaciones del río: el de la retención, cuando el valle fluvial estaba menos ocupado; el del desagüe y el de la regulación hídrica integral; cuando la cuenca estaba más urbanizada. En esa lógica, el texto se organiza en tres apartados y presenta reflexiones de discusión al final.

\section{Retención}

El dibujo de la forma del río en 1972 (Figura 4), ${ }^{7}$ muestra un espejo de agua de aproximadamente 180 ha en las nacientes del río y a una cota de 17,5 m I.G.N. (Ministerio de Economía Provincia de Buenos Aires 1985) que no era parte de su configuración natural. Se trata de la Laguna San Francisco, que se conformó a partir de la construcción de la represa Ingeniero Roggero, una solución técnica ideada a fines de la década de 1950 frente al problema de las inundaciones en las zonas de Merlo, Moreno y Paso del Rey, localizadas a ambos márgenes del río y sobre el eje de expansión metropolitana noroeste (Sadañiowski 2003).

\footnotetext{
${ }^{7}$ Elaborado a partir del redibujo de la forma del río en la secuencia de 16 fotogramas en escala 1:20.000 tomados en 1972 por el Departamento Fotogramétrico del Ministerio de Obras Públicas de la Provincia de Buenos Aires (actualmente el Ministerio de Infraestructura y Servicios Públicos).
} 


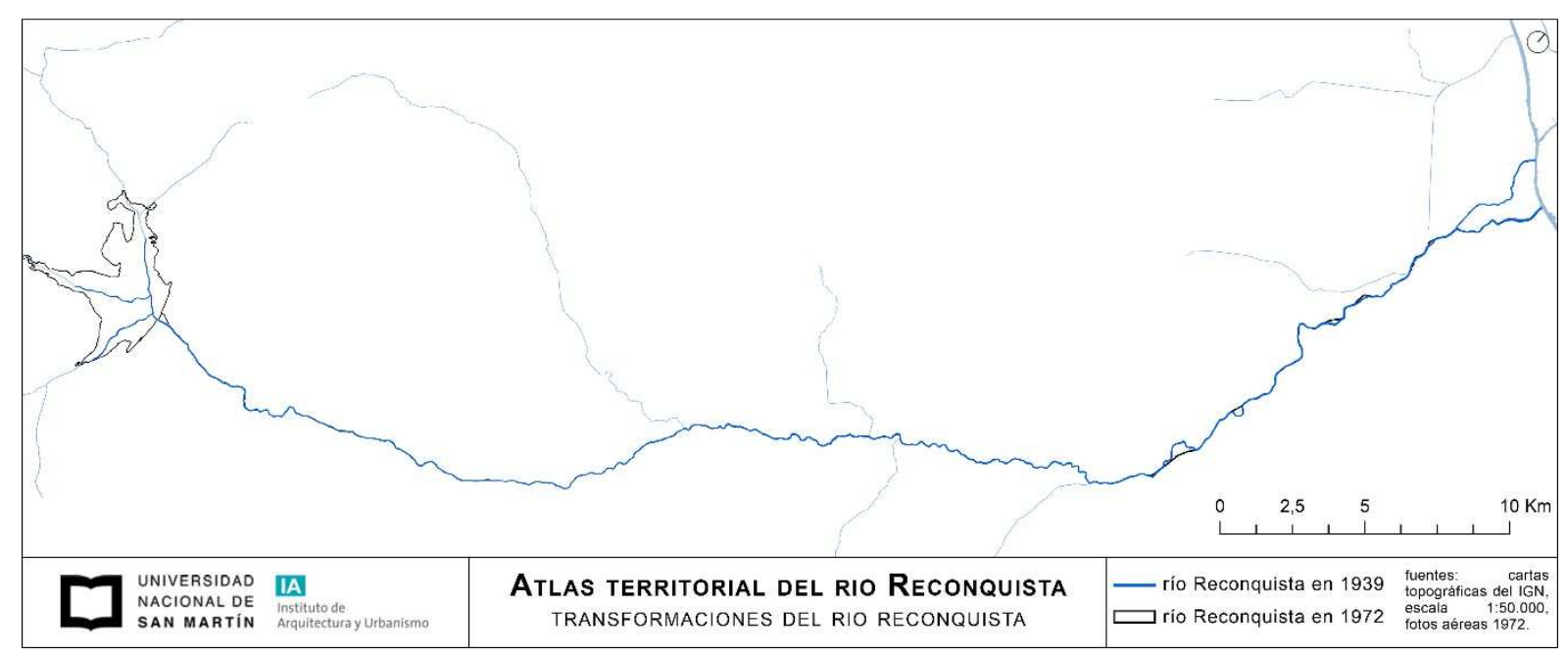

Figura 4 - El río Reconquista en 1939 y 1972. Fuente: Elaboración propia.

Si bien ya existían los pequeños asentamientos de Moreno y Merlo en torno a las estaciones del ferrocarril, el poblamiento más intenso de la zona se produjo con el primer ciclo de expansión metropolitana de Buenos Aires que se consolidó hacia la década de 1940, sustentado en la industria sustitutiva de importaciones, los loteos baratos en la periferia y el transporte ferroviario subsidiado (Torres 1993). El trazado del Ferrocarril Oeste de Buenos Aires (actual línea Sarmiento) había priorizado las tierras más altas, pero debió cruzar transversalmente la cuenca Reconquista, y lo hizo por un vado conocido como "Paso del Rey" (pues había sido uno de los pasos de los caminos reales desde Buenos Aires hacia el interior del Virreinato del Río de La Plata). Fue sobre esas condiciones, y las dadas por la instalación de pequeñas industrias que se beneficiaban de su proximidad al río, que se desarrollaron las poblaciones homónimas.

El dibujo de las áreas ocupadas por la urbanización en la década de 1950 (Figura 5) ${ }^{8}$ muestra que el eje noroeste se desarrolla sobre un perfil relativamente elevado dentro de la cuenca (entre 12,5 y 15 m I.G.N.). Sin embargo, las áreas ocupadas llegaban hasta los bordes del río lo cual representaba, para esos afincamientos, un elevado riesgo de sufrir los constantes desbordes de un río de llanura. Aguas abajo, el territorio estaba menos ocupado: primero es la cota $10 \mathrm{~m}$ y luego la 5, lo que delimita el avance de la urbanización hasta la

\footnotetext{
${ }^{8}$ Elaborado a partir de la confrontación de dos fuentes gráficas. Por un lado, las cuatro cartas topográficas del I.G.N. precitadas (y cuya actualización parcial se realizó a fines de la década del 50) que corresponden al recorrido del río; y por otro, las "áreas edificadas" de la Aglomeración Gran Buenos Aires cartografiadas por Vapñarsky (2000) a partir de un mosaico aerofotográfico de 1967.
} 
zona donde la barranca desaparece, en continuidad con la ocupación consolidada de la costa del río de La Plata, cerca de la desembocadura al Luján.

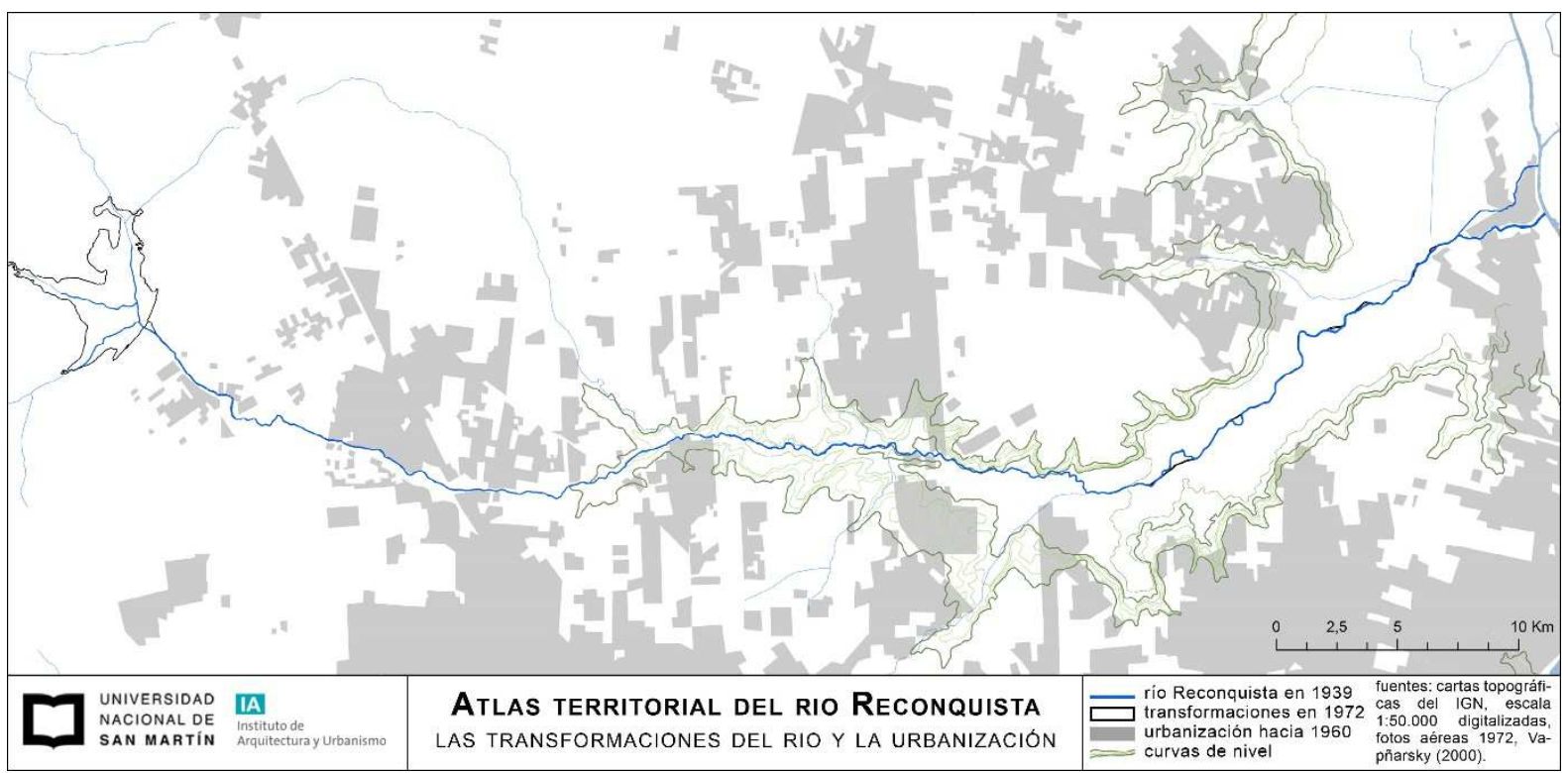

Figura 5 - La ocupación del suelo por la urbanización entre fines de las décadas de 1950 y 1960. Fuente: Elaboración propia.

Las periódicas inundaciones de todo el área y, en particular, de las localidades de Moreno, Merlo y Paso del Rey, motivaron la elaboración del "Estudio Hidrológico del Río Reconquista" realizado entre 1959 y 1960 por el recientemente creado Departamento de Hidrología de la Dirección de Hidráulica provincial ${ }^{9}$ a cargo del Ing. Carlos Roggero.

A pesar de que la disyuntiva entre la retención y el desagüe ya venía discutiéndose desde fines del siglo XIX (cuestión de la cual da cuenta la propuesta del Ing. Florentino Ameghino (Ministerio de Asuntos Agrarios de la Provincia de Buenos Aires 1984), era claro previo al estudio que la solución al problema de las inundaciones consistía en regular, mediante la construcción de diques y lagunas, el caudal de agua del río, en un momento desarrollista y de afianzamiento de la ingeniería hidráulica en Argentina en que se construyeron numerosos embalses y diques para aprovechamiento hidroeléctrico o regulación hídrica (Rausch 2016).

En ese marco, el estudio se propuso realizar los cálculos necesarios para proyectar la construcción de una represa que permitiera retener los excedentes hídricos de la región durante las épocas de crecidas. Para tal fin se valió de los datos hidrométricos recogidos

\footnotetext{
${ }^{9}$ Dentro del Ministerio de Obras Públicas.
} 
durante las repetidas inundaciones ocurridas a lo largo del año 1959, que afectaron a un área de $180 \mathrm{~km}^{2}$ y a 150.000 habitantes (Dalairac 1997), que -junto con los pluviométricospermitirían generar "fiel estadística" (utilizando este territorio fluvial como un laboratorio experimental), poner a punto métodos de hidrología moderna y organizar las actividades e investigaciones del nuevo organismo.

La propuesta de retención del agua partió de considerar el avance de la urbanización de Buenos Aires sobre el valle del río Reconquista. En el tramo inferior, donde ya se registraban algunas radicaciones fabriles y obreras, estimó "difícil proveerle una solución completa económicamente viable por el momento; sólo puede asegurarse que se beneficiará en la medida en que sean reducidos los efectos nocivos de las ondas provenientes de aguas arriba" (Ministerio de Obras Públicas de la Provincia de Buenos Aires 1964:11). En cambio, para el tramo medio (donde la urbanización había avanzado sobre los bordes del río) una solución técnica resultaba viable y consistía en la combinación de un embalse de regulación y la canalización del curso de agua.

Desde esa clave, la construcción de la represa Roggero fue iniciada en 1967 y concretada en 1972 (Figura 6). A ella se sumaron, posteriormente, dos obras de presas menores en los tributarios del Reconquista: la presa Marín sobre el arroyo La Choza, y la presa El Durazno, en el arroyo homónimo. Si bien lograron reducir los picos de crecida máxima a una recurrencia de 100 años, la puesta en funcionamiento del sistema de retención -en su conjunto- tuvo algunos vaivenes políticos y técnicos hasta la década de 1990 (Sadañiowski 2003).

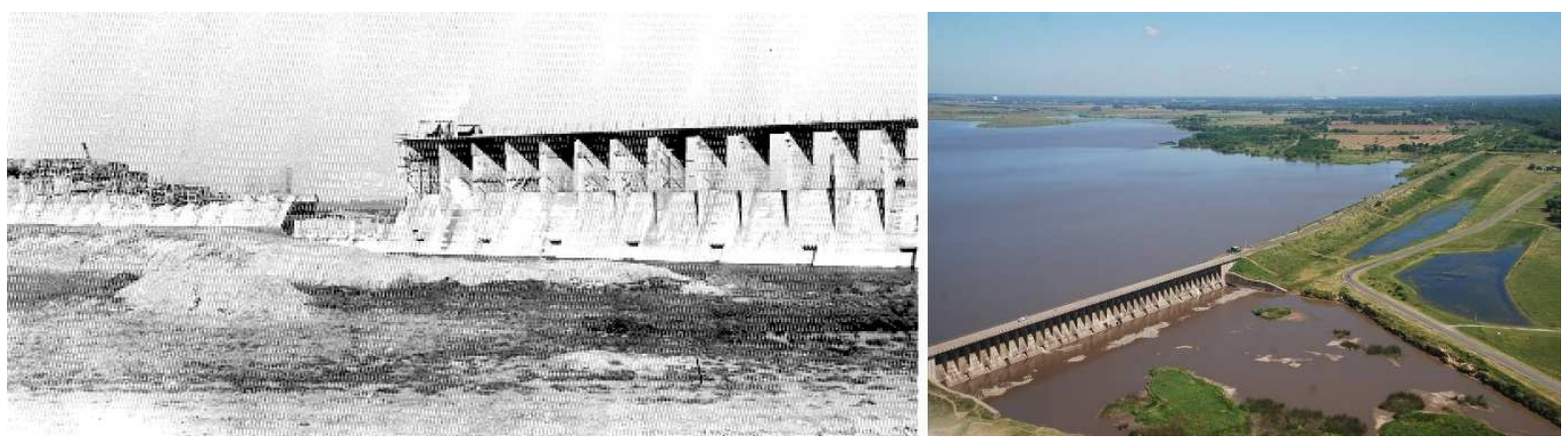

Figura 6 - Imágenes de las represas Roggero y la Laguna San Francisco a principios de la década de 1970, cuando aún estaba en construcción (izquierda) y en la actualidad (derecha). Fuentes: Sadañiowski (2003) y Municipalidad de Merlo. 


\section{Desagüe}

A pesar de que el territorio fluvial del Reconquista siguió siendo escenario de inundaciones, no fue sino hasta la gran inundación de 1985 que el problema volvió a ocupar un sitio relevante de la agenda pública.

El dibujo del río en 1985 (Figura 7) ${ }^{10}$ muestra que próximo a su desembocadura se desvió su curso aguas arriba del rio Luján, hacia la Pista Nacional de Remo. Éste era un espejo de agua construido con fines deportivos a principios de la década de 1970 y pensado como vertedero aliviador del Reconquista.

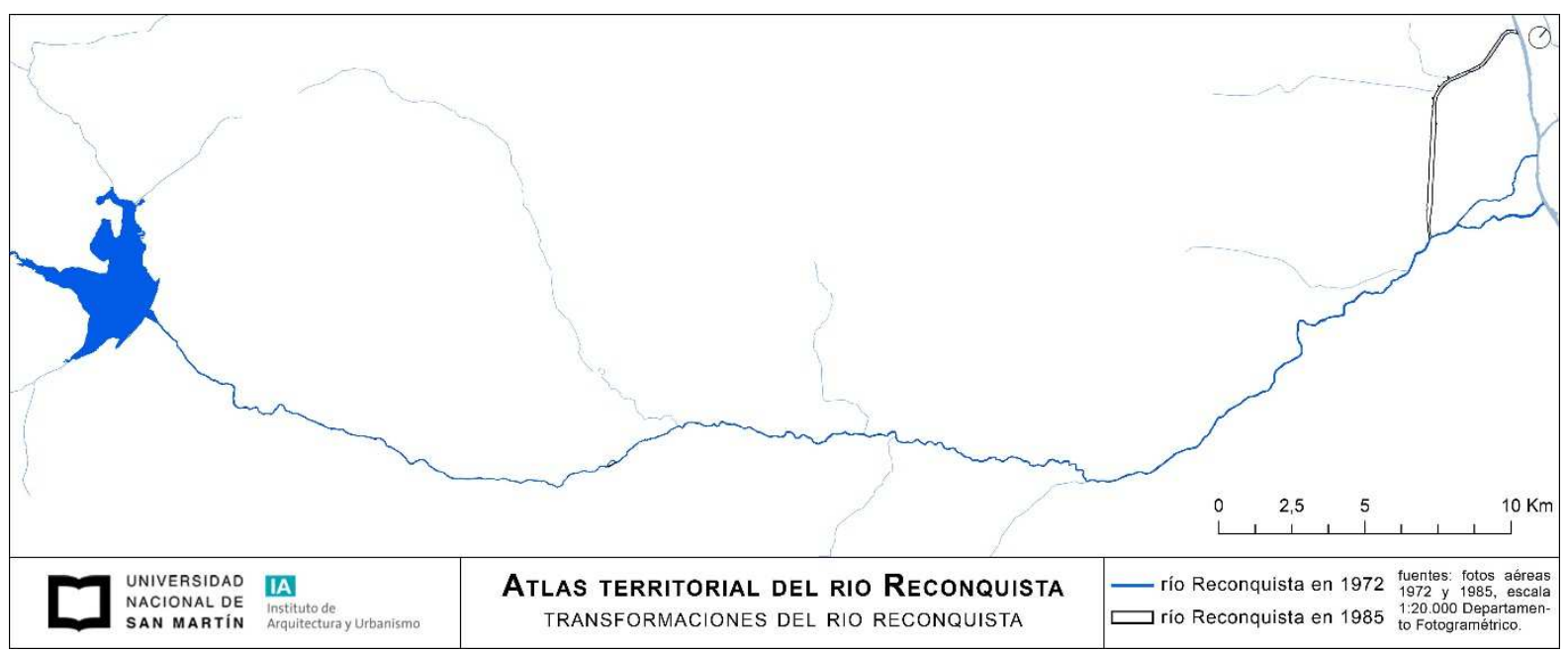

Figura 7 - El río Reconquista en 1972 y 1985. Fuente: Elaboración propia.

La construcción de la Pista Nacional de Remo fue posible gracias a una donación de tierras que realizó Pacheco Alvear a favor de la Municipalidad de Tigre en el año 1968. En 1972, la Municipalidad aceptó tal donación y la condicionó a que el lugar se destinara a la práctica de deportes náuticos "de nivel competitivo, de entrenamiento, de aprendizaje y recreativo" (Ordenanza 742/72 de la Municipalidad de Tigre). Según establecía la norma, sólo podría utilizarse como aliviador de inundaciones en situaciones críticas, dado que en su otro extremo se comunica con el arroyo Guazú-Nambí (canalizado también) que, tras un corto recorrido por esa zona de humedales, desemboca en el río Luján. Pero la gran inundación de 1985, que alcanzó a $119 \mathrm{~km}^{2}$ (una superficie 34\% menor que la de 1959 que, sin embargo, afectó al doble de población), y la dificultad de desagotar las aguas contaminadas de las

\footnotetext{
${ }^{10}$ Confeccionado a partir del calcado de las 15 aerofotografías de escala 1:20.000 tomadas por la Dirección de Hidráulica (Provincia de Buenos Aires) a propósito de la gran inundación de 1985.
} 
áreas urbanizadas en el tramo inferior del río (principalmente Tigre y San Fernando), llevó al Gobierno Provincial a destruir el vertedero que parcialmente aislaba el curso del río de la Pista Nacional de Remo, constituyendo -más que un aliviador de inundaciones críticas- un desagüe artificial y permanente del Reconquista (Suárez y Lombardo 2012).

En el dibujo de la urbanización en 1997 (Figura 8), ${ }^{11}$ la curva de nivel de 10 m I.G.N. encierra un área de tamaño irregular que acompaña el recorrido del río y se ensancha hacia el valle inferior del Reconquista. El ámbito es, sobre cada margen del río, de ancho variable de acuerdo a sus perfiles asimétricos: la margen derecha presenta un valle de inundación más amplio que la izquierda, lo cual plantea diferentes escenarios para el avance de la urbanización. En efecto, la urbanización ocupó progresivamente las tierras bajas de la margen derecha dejando un borde irregular, sólo flanqueado por las crecidas del río. La ocupación de ese suelo corresponde a la instalación de grandes infraestructuras (tal los rellenos sanitarios del CEAMSE ${ }^{12}$ y la Autopista del Buen Ayre), de industrias, la extensión de la cuadrícula más tradicional, primero, y la expansión de asentamientos informales, luego (es el caso de numerosos barrios del partido de San Martín y los bajos de San Isidro). De la margen opuesta, donde se observa una terraza alta, se dan dos situaciones contrastantes: por un lado, hay un amplio terreno desocupado que corresponde a las instalaciones del complejo militar Campo de Mayo; y por otro, una zona ocupada por la expansión de la localidad de Don Torcuato sobre el valle del río. Aguas abajo, en una superficie amplia de la llanura aluvial que adquiere una distancia de hasta $6 \mathrm{~km}$, el suelo se encuentra ocupado hasta las orillas del río por los poblados de General Pacheco y, en particular, el barrio Troncos del Talar (de tejido mixto residencial-industrial), el área de Tigre, la localidad de Rincón de Milberg y el partido de San Fernando (en particular el barrio Virreyes Oeste). Es precisamente en torno de la confluencia de esas áreas urbanizadas donde el Reconquista se desvía hacia el Canal Aliviador, un nodo en tierras bajas afectado gravemente por la inundación de 1985 (Figura 9).

\footnotetext{
${ }^{11}$ Realizado a partir del calcado y redibujo de las aerofotografías que tomó la Dirección Provincial de Hidráulica (Provincia de Buenos Aires) para registrar la gran inundación del 85, siguiendo el criterio espacial de delimitación utilizado por Vapñarsky (2000) para las "áreas edificadas", que tiene en cuenta la forma material de la aglomeración.

${ }^{12}$ Las siglas corresponden a: Coordinación Ecológica Área Metropolitana Sociedad del Estado, una empresa mixta creada en la década de 1970 para conformar el Cinturón Ecológico Metropolitano y disponer el relleno de la basura generada en la Ciudad Autónoma de Buenos Aires y los municipios conurbados.
} 


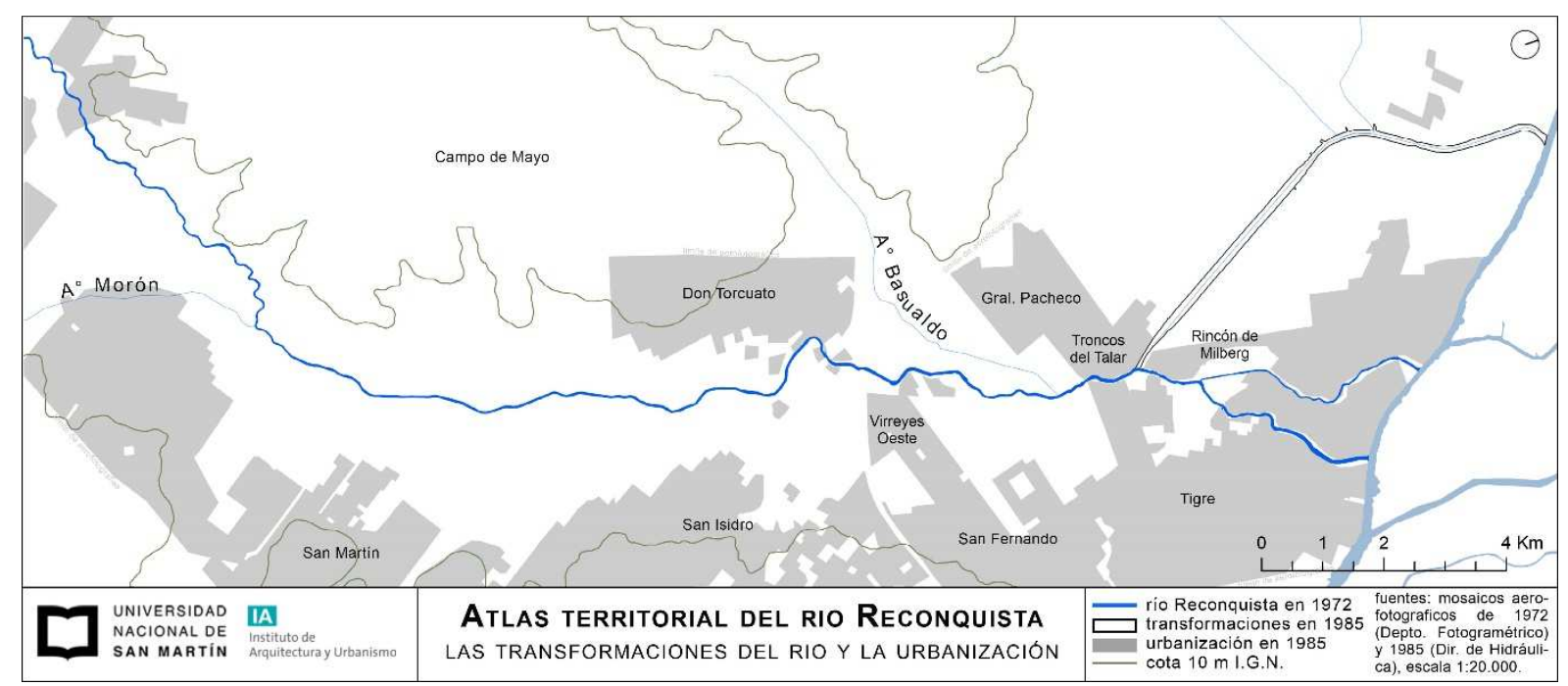

Figura 8 - La ocupación del suelo por la urbanización en 1985. Fuente: Elaboración propia.

Ese mismo año el Ministerio de Economía del Gobierno Provincial elaboró un estudio técnico-económico de la inundabilidad de la cuenca del río Reconquista cuya síntesis se publicó en el documento "Cuenca inundable Río Reconquista. Datos básicos". El mismo partió de considerar la creciente ocupación de los valles de inundación en los tramos medio e inferior; no solo porque se trata de ocupaciones directamente afectadas por las crecidas del río, sino porque también cambian e incrementan las escorrentías superficiales. Cabría sumar a ello, la urbanización de la cuenca en general, que genera desbalances en la hidrografía superficial-subterránea por la captación de agua de consumo (que en buena medida se realizaba de las napas subterráneas) y el aporte de mayores caudales de efluentes industriales, pluviales y cloacales (Herrero y Fernández 2008). El estudio ponderó los costos de las inundaciones, el de las obras necesarias y sus beneficios, considerando que en la cuenca habita aproximadamente el $12 \%$ de la población del país y en ella se genera casi el $50 \%$ del PBI del Gran Buenos Aires y más del 24\% del total provincial.

En ese marco, planteó que la obra de la represa Roggero constituía "una solución parcial a la problemática hídrica" y por lo tanto propuso que se complementara con otras "acciones correctivas" que debían implementarse entre la presa Roggero y el río Luján, como área de "tratamiento complejo debido a los múltiples factores en juego". Tales acciones incluían la construcción de aliviadores, el dragado de los cauces, la realización de entubamientos, obras de defensa, lagunas reguladoras, control de mareas y forestación para el control de los procesos erosivos. En ese sentido, si bien la apertura definitiva del Canal Aliviador 
respondió a una coyuntura muy específica, la idea de un aliviador que sirviera de desagüe de la cuenca baja en momentos críticos se enmarcaba en una estrategia de actuación más integral que comenzaría a tomar forma como programa de regulación hídrica hacia fines de la década de 1980.

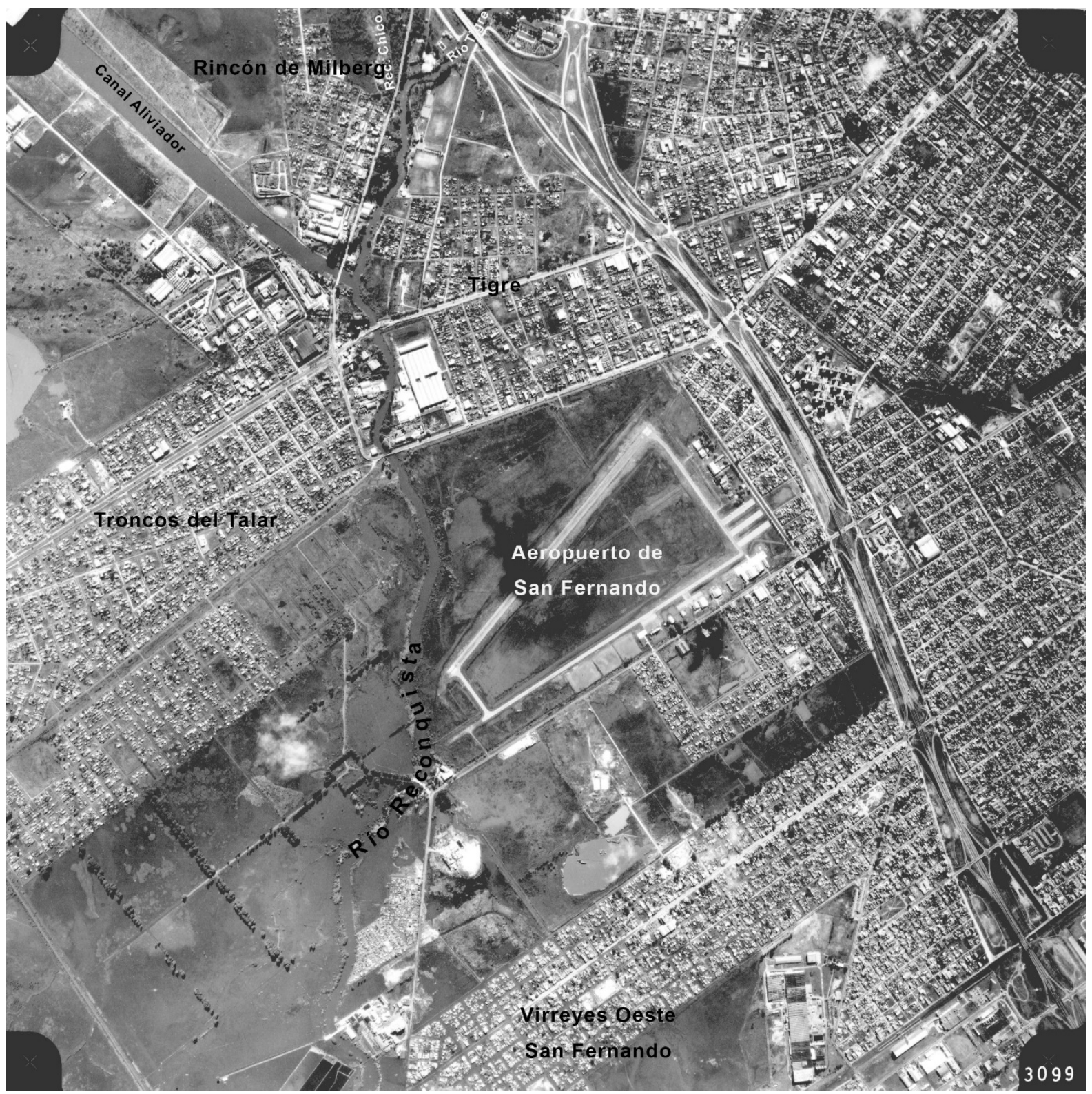

Figura 9 - Foto aérea de la zona de Rincon de Milberg-Tigre-Troncos del Talar durante la inundación de 1985. Fuente: Dirección de Hidráulica, Provincia de Buenos Aires. 


\section{Regulación hídrica integral}

El dibujo del Reconquista en 2010 (Figura 10$)^{13}$ muestra que, respecto de su configuración en 1985, el río fue canalizado, ensanchado y rectificado desde la represa Roggero hasta el Canal Aliviador. Las transformaciones responden a la ejecución del Programa de Saneamiento y Control de las Inundaciones de la cuenca del río Reconquista, desde el año 1996. Se destaca una nueva canalización, previo a la desviación del Canal Aliviador, que corresponde a la obra del "Canal DPH", iniciada previamente por el Gobierno Provincial y finalizada a principios de los 2000 en el marco del Programa.

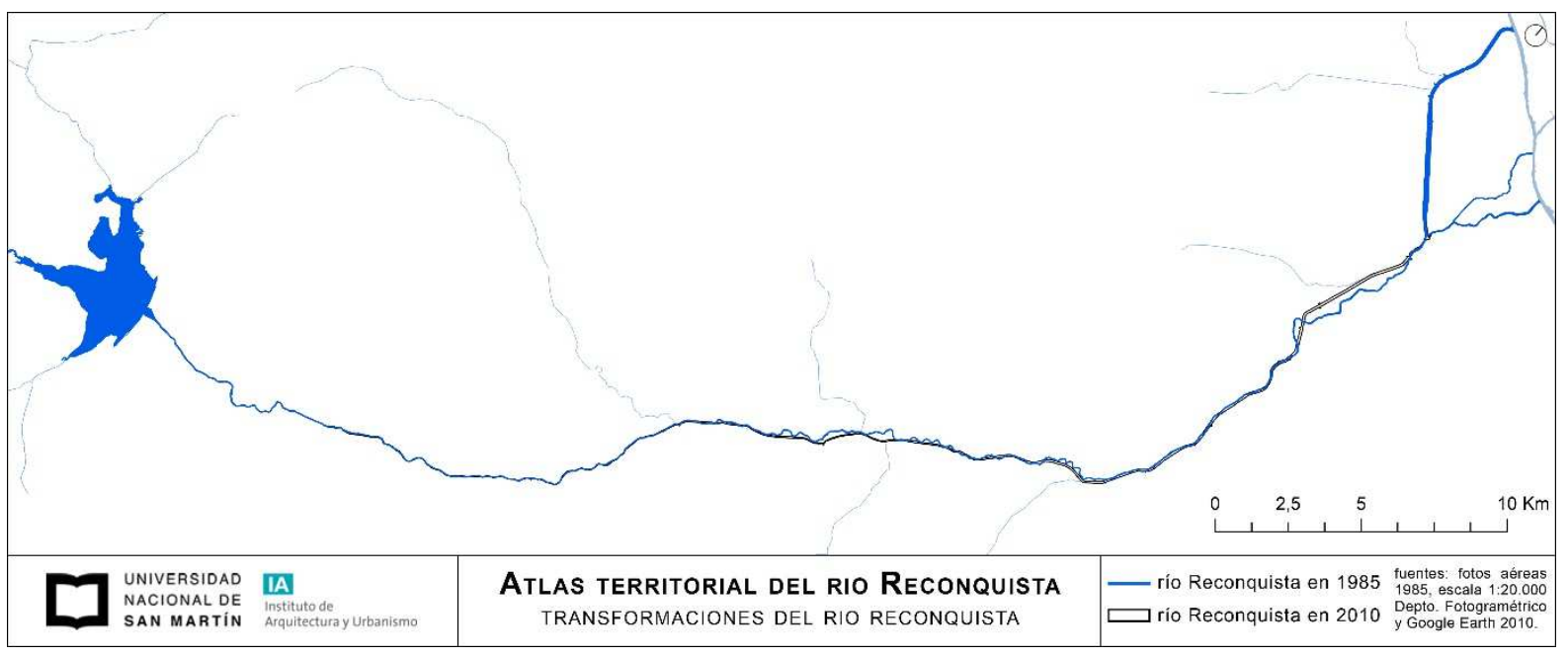

Figura 10 - El río Reconquista en 1985 y 2010. Fuente: Elaboración propia.

El plan de obras se elaboró por la Dirección Provincial de Hidráulica a partir de considerar las graves inundaciones que afectaban a la cuenca Reconquista. En particular, tomó como caso más reciente la de 1985, sobre la cual se centró el estudio de inundabilidad que había realizado el Ministerio de Economía provincial.

Aquel estudio ya ponía de relieve la importancia de pensar en sistemas con subsistemas y en soluciones integrales, frente a la fragmentación en el tiempo y en el espacio de las intervenciones anteriores. Tal enfoque se enmarcaba en las ideas del momento, pues junto con el interés por la conservación del medio ambiente y los recursos naturales, el desarrollo económico y el mejoramiento de la calidad de vida, en el ámbito internacional se instalaba la noción de "sistemas complejos" y el interés por diseñar estrategias integrales capaces de

\footnotetext{
${ }^{13}$ Elaborado a partir del calcado de las imágenes satelitales que provee Google Earth.
} 
actuar sobre las múltiples dimensiones de los problemas. ${ }^{14}$ Así se entendieron las inundaciones de la cuenca: como un problema complejo y multicausal que debía ser abordado con un paquete de obras y acciones articuladas. Desde esa clave, el Programa incluyó no solo un conjunto de intervenciones físicas orientadas a reducir el riesgo de inundaciones, sino también una serie de medidas para iniciar la descontaminación de los cursos fluviales y acciones de carácter institucional. ${ }^{15}$

El problema se centraba en la recurrencia de inundaciones y el hecho de que éstas se producían con aguas contaminadas, pues como indica el diagnóstico del Programa, "constituyen una grave amenaza para la salubridad de la población" (Dalairac 1997:403). La contaminación del agua y del suelo, producida tanto por el vertido de efluentes industriales con nulo -o escaso- tratamiento, los líquidos cloacales volcados en crudo y la basura acumulada en arroyos y tierras bajas, ya no sólo afectaba a quienes habitaban asentamientos informales en esas tierras ambientalmente degradadas, sino a áreas más extensas sobre las cuales -con cada desborde del río- se dispersaban los contaminantes. Asimismo, éstos afectaban no sólo a la población asentada en la planicie de inundación, sino también a zonas que -aunque naturalmente no pertenecían a ésta- fueron incorporadas por efecto de la interposición de obstáculos antrópicos como puentes, caminos, terraplenes o desagües pluviales producto de un "importante e imprevisto crecimiento urbano" (Dalairac 1997:404) que se había producido en los tramos medio e inferior del río.

En efecto, el dibujo de la urbanización en 1997 (Figura 11$)^{16}$ muestra una ciudad que fue avanzando, cada vez más, sobre las tierras bajas. Es claro en este momento que la cota ya no limita la urbanización como lo hacía antes pues grandes áreas del valle de inundación fueron ocupadas. La bibliografía da cuenta de tres usos principales. Primero, la producción de algunas urbanizaciones cerradas y complejos deportivos como clubes de rugby y campos de golf que, por requerir grandes superficies, utilizan tierras inundables de bajo valor

\footnotetext{
${ }^{14}$ Primera Conferencia sobre Medio Ambiente Humano (Estocolmo, 1972), Conferencia Internacional sobre Población y Desarrollo (Bucarest, 1974), Conferencia sobre los Asentamientos Humanos ("Hábitat I", Vancouver, 1976), Conferencia de las Naciones Unidas sobre el Agua (Mar del Plata, 1977).

${ }^{15}$ En su inicio, se trataba de un programa de control de las inundaciones, de acuerdo a los criterios ya plasmados en el informe "Cuenca inundable Río Reconquista" que elaboró el Ministerio de Economía en 1985; pero incluyó aspectos ambientales e institucionales en el proceso de negociación de una línea de financiamiento internacional con el Banco Interamericano de Desarrollo (BID).

${ }^{16}$ Realizado a partir del calcado y redibujo de las aerofotografías que tomó el Departamento Fotogramétrico de la Provincia de Buenos Aires en escala 1:40.000, replicando la delimitación de las "áreas edificadas" ya enunciada.
} 
inmobiliario. Habitualmente, este tipo de desarrollos ciegan bañados naturales, modifican la hidrografía superficial y la topografía al construir pólders perimetrales. Segundo, la expansión de asentamientos informales sobre tierras inundables y contaminadas, sin infraestructura ni servicios urbanos. Tercero, la instalación de rellenos de basura, tanto los grandes complejos del CEAMSE, como una multiplicidad de pequeños basurales informales (y las llamadas "quemas" donde se incineraba clandestinamente la basura) que muchas veces se dan en contunuidad o en superposición con los asentamientos.

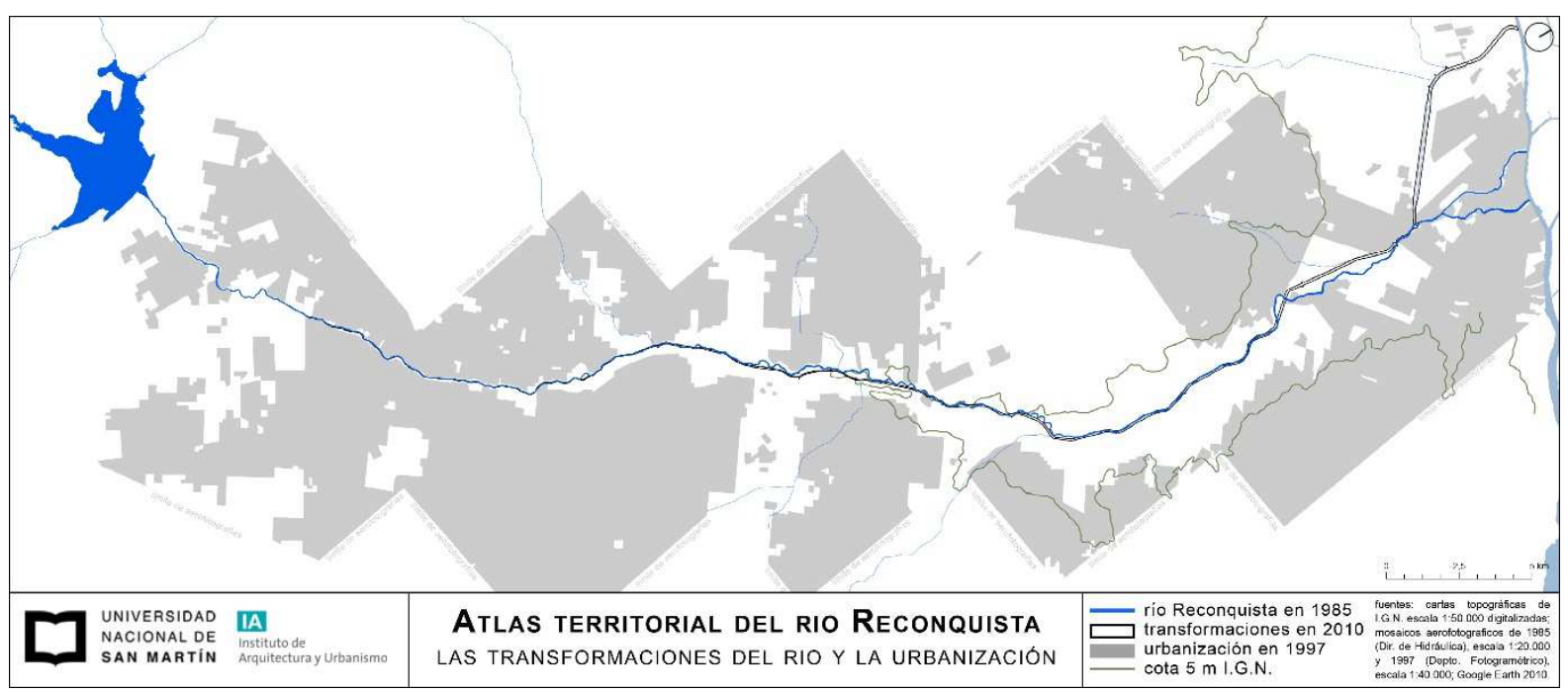

Figura 11: La ocupación del suelo por la urbanización en 1997. Fuente: Elaboración propia.

Es en ese complejo escenario en el cual se ejecutaron las obras de gestión hídrica integral desde mediados de la década de 1990 hasta el 2004. Las mismas consistían, por un lado, en numerosas canalizaciones del río en diferentes tramos que lo ensanchan hacia la desembocadura (tramo superior, tramo medio, Canal DPH y adecuación del Canal Aliviador, entre otros), que surgían de los cálculos de recurrencias de inundaciones de 10, 25 y 50 años. Éstos indicaban que los caudales del río debían ser de 616, 728 y $907 \mathrm{~m}^{3}$ para los tramos medio, inferior y Canal Aliviador (Figura 12). ${ }^{17}$ Asimismo, el fondo del cauce del río naturalmente plano- fue excavado para lograr que el agua corriera a mayor velocidad. Tales obras se complementaron con la canalización de algunos tributarios (arroyos Basualdo, Los Berros y Soto) y la construcción de terraplenes de protección en ciertas áreas para impedir

\footnotetext{
${ }^{17}$ De acuerdo a Dalairac (1997), la sección original del río poseía un ancho de fondo medio del orden de los 20 $\mathrm{m}$. Con las canalizaciones se propusieron $15 \mathrm{~m}$ en el tramo superior, 30 en el tramo medio (tomado desde el Arroyo Las Catonas), $50 \mathrm{~m}$ en el tramo inferior (desde el arroyo Las Catonas hasta el Canal Aliviador) y $100 \mathrm{~m}$ en el Canal Aliviador y su desembocadura al río Luján.
} 
el anegamiento de las zonas bajas adyacentes. La canalización del río y de sus tributarios implicó rectificar los numerosos meandros que ralentizaban el escurrimiento del agua.

Por otro lado, se realizaron obras de menor envergadura, aunque igualmente importantes para mejorar el funcionamiento de la cuenca como sistema hídrico: construcción de puentes nuevos y adecuación de los existentes a los nuevos anchos y recorridos del rio; instalación de estaciones de bombeo para evacuar las áreas que por la presencia de los terraplenes no son descargadas por gravedad; y limpieza, mejora o acondicionamiento de canalizaciones, zanjeos y cunetas.

El Programa anunciaba que la implementación de esas acciones -que serían proyectadas y ejecutadas por la Unidad de Coordinación del Proyecto río Reconquista (UNIREC), un organismo creado ad hoc- permitiría en diez años el uso recreativo del río y sus márgenes con contacto directo, y el desarrollo de la biota acuática y ribereña. Pero mientras las obras hidráulicas fueron completadas, reduciendo sensiblemente el riesgo de inundaciones, el saneamiento ambiental y las acciones institucionales fueron cuestiones poco atendidas (Defensor del Pueblo de la Nación 2007).
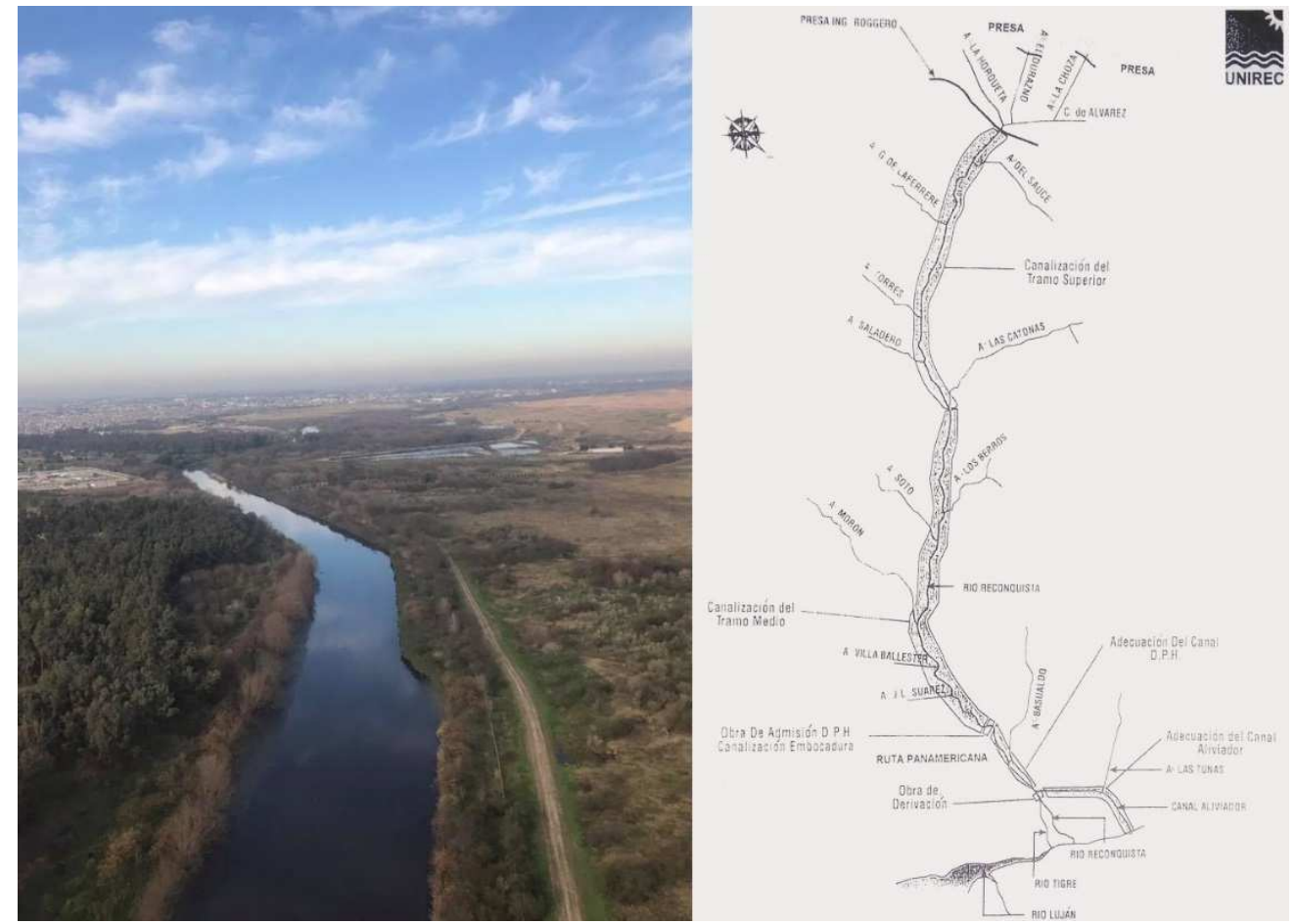

Figura 12: Imágenes de la ejecución del Programa de Saneamiento Ambiental y Control de las Inundaciones de la cuenca del río Reconquista. Fuentes: Comité de Cuenca del río Reconquista y Unidad de Coordinación del río Reconquista. 


\section{Reflexiones finales}

Los dibujos del Reconquista y de la ocupación del suelo en una secuencia histórica dan cuenta de las formas cambiantes del río y del avance de la urbanización metropolitana. En una primera mirada, al comparar la configuración natural del río y la actual, es posible advertir que se borraron meandros, se ensanchó su cauce, se rectificaron sus bordes y se sumaron algunos elementos artificiales, como la Laguna San Francisco en las nacientes y el Canal Aliviador próximo a su desembocadura. Tales transformaciones se debieron a grandes obras de infraestructura hidráulica. Pero éstas no se dieron en abstracto, sino en una compleja relación con la creciente urbanización del territorio. En efecto, los dibujos de la urbanización permiten ver cómo -en simultáneo- se fueron ocupando las tierras del valle de inundación, primero en el tramo superior, luego en el medio e inferior. Es a partir de examinar esas relaciones que nos hemos referido a tres momentos cronológicoproblemáticos de las transformaciones del territorio fluvial del Reconquista.

En un primer momento, a pesar de que la cuenca estaba escasamente ocupada en sus tramos medio e inferior, el eje noroeste de expansión metropolitana había cruzado el Reconquista en una zona baja vulnerable a las crecidas del río por las avenidas provenientes del tramo superior en épocas de lluvias. Las recurrentes inundaciones de las poblaciones que se localizaban sobre ese eje promovieron la elaboración de un estudio para la construcción de una laguna reguladora de su cauce que permitiría, esencialmente, la retención del agua en momentos críticos. En tanto la idea dominante en las políticas de tipo hidráulica de ese momento era la construcción de represas para el aprovechamiento energético o la regulación hídrica, el estudio para la construcción de la represa Roggero en las nacientes del Reconquista permitiría, no sólo realizar los cálculos matemáticos necesarios para tal cometido, sino fundamentalmente poner a punto las técnicas y los métodos de un organismo técnico recientemente creado.

Pero a pesar de la envergadura de la obra, y que oportunamente se ejecutaron dos menores que la complementaron, las inundaciones siguieron ocurriendo. Es cierto que las superficies inundables se habían reducido sensiblemente, pero también la cantidad de población afectada iba en aumento pues se seguía ocupando el territorio fluvial. Esto ponía a la población allí radicada en situación de riesgo, pero además modificaba las escorrentías 
naturales $y$, también, incorporaba aguas muy contaminadas por efluentes industriales y cloacales de una urbanización que se expandía sin infraestructura de servicios a expensas de la calidad de los recursos naturales. Ante tales condiciones, en un segundo momento, fue necesario desaguar las aguas contaminadas anegadas en los barrios radicados en las tierras más bajas del valle aluvional.

La decisión de destruir el pequeño vertedero que separaba al río de la Pista Nacional de Remo pudo resultar una solución rápida ante una necesidad urgente. Sin embargo, luego se enmarcó en una estrategia que se suponía de más largo aliento: la regulación hídrica integral, bajo la premisa conceptual de que la cuenca funciona como un sistema y que las causas de las inundaciones son múltiples.

En ese sentido, en un tercer momento, cuando el valle del Reconquista ya estaba muy ocupado en todos sus tramos, la combinación de diferentes tipos de proyectos hidráulicos, como canales artificiales, excavaciones del cauce, rectificaciones, ensanches que adecúan el ancho del río a mayores caudales hacia la desembocadura evitando escollos, terraplenes e instalación de bombeadores de agua, principalmente; junto con los de saneamiento y gestión institucional; se presentaban como la ecuación que permitiría resolver el problema de las inundaciones de forma definitiva. El costo de tales obras, que fue afrontado gracias a un crédito internacional, se justificaba en la medida en que las inundaciones implicaban mayores pérdidas y no permitían el pleno desarrollo de la región.

Ahora bien, ¿qué iluminan esos momentos de las procesos de construcción del espacio metropolitano?

Por un lado, dan cuenta del largo proceso a través del cual se fue desarrollando la forma de pensar y operar en los ríos urbanos de la RMBA.

Ciertamente, la transformación de áreas inundables para la ocupación urbana mediante diferentes técnicas hidráulicas tiene una historia tan extensa como la propia historia de la urbanización (Ríos 2010). Pero el tipo de solución pensada fue variando de acuerdo a las ideas de cada momento histórico. En ese sentido, si primero las intervenciones hidráulicas fueron focalizadas, luego se tendió a la integralidad, enfoque que buscó articular diferentes estrategias, desde la retención del agua hasta la regulación de la cuenca hídrica en su conjunto. 
La perspectiva de la integralidad, relacionada con la mirada sistémica -ampliamemte discutida desde mediados del siglo XX- busca la coherencia y la coordinación entre diferentes elementos (físicos, económicos y sociales) para lograr mejores resultados. Dentro de esa lógica, la regulación hídrica integral y la gestión integrada de cuencas hidrográficas ganaron fuerza en las agendas públicas desde la década de 1990 (Porto y Porto 2008), sumándose a diferentes campos de actuación del Estado, como el ordenamiento territorial, el hábitat o la pobreza.

Por otro lado, muestran cómo los territorios fluviales se fueron construyendo como bordes del territorio metropolitano (Potocko 2017). Primero, porque debido a su inundabilidad, fueron un obstáculo para la expansión de la ciudad; luego, porque se fueron constituyendo en áreas de oportunidad para la instalación de una serie de usos del suelo que requerían grandes superficies o que encontraron en los valles inundables tierras más baratas o susceptibles de ocupación informal. Esas áreas de oportunidad surgieron a partir de que las grandes obras hidráulicas lograron reducir sensiblemente el riesgo de inundaciones; aunque, como vimos, no pudieron evitar que las nuevas tierras que se iban ocupando fueran afectadas por las crecidas del río. En suma, en tanto insumo para la intervención en el territorio, muestran las relaciones que se tejieron desde mediados del siglo XX entre las soluciones técnicas, las demandas y los problemas de un espacio cada vez más urbanizado.

\section{Referências bibliográficas}

ALSINA, Griselda y HERRERO, Ana Carolina. Relevamiento total de industrias en la cuenca del río Reconquista y georreferenciación de las de Tercera Categoría según su nivel de complejidad ambiental (Ley 11.459). Relación entre actividad industrial y grado de contaminación de la cuenca. En Segundas Jornadas de Investigación, Los Polvorines, Buenos Aires, 2000. Los Polvorines, Buenos Aires: Universidad Nacional de General Sarmiento.

CASTAÑÉ, Patricia, LÓEZ, Carolina, OlgUIN, Héctor, PUIG, Alba, ROVEDATTI, María, TOPALIÁN, Mirta, y SALIBIÁN, Alfredo. Caracterización y variación espacial de parámetros fisicoquímicos y del plancton en un río urbano contaminado (Río Reconquista, Argentina). Revista Internacional de Contaminación Ambiental. 1998, 14(2), 69-77. ISSN 0188-4999.

CATENAZZI, Andrea, CARDOZO, Lucía, PERALTA, Verónica y CAÑELLAS, Estela. Historias minimas sobre el borde del río Reconquista. En $3^{\circ}$ Congreso Internacional de Estudios Urbanos "Situación y Perspectivas de la Vivienda y el Hábitat en Argentina y América Latina". URBARED-MUNDO URBANO. 2017. Sin publicar.

CRAVINO, Cristina, FOURNIER, Marisa, Neufeld, María Rosa y SOLDANO, Daniela. Sociabilidad y micropolítica en un barrio bajo planes. En Andrenacci, Luciano, Cuestión social y política social en el Gran Buenos Aires. La Plata: Ediciones al margen; Los Polvorines: Universidad Nacional de General Sarmiento, 2002, 57-80. 
CURUTCHET, Gustavo, GRINBERG, Silvia y GUTIÉRREZ, Ricardo. Degradación ambiental y periferia urbana: un estudio transdiciplinario sobre la contaminación en la región metropolitana de Buenos Aires. Ambiente \& Sociedade. 2012, Vol. 15, no. 2, DOI 10.1590/s1414-753x2012000200010. ISSN 1809-4422.

DALAIRAC, Hugo. Saneamiento Ambiental y Control de las Inundaciones de la cuenca del Río Reconquista. En Mercosur. Proyectos para empresas de ingeniería, constructoras e inversoras nacionales y extranjeras, Buenos Aires, 17, 18 y 19 de junio de 1997. Buenos Aires: Bureau de Investigaciones Empresariales. Pp. 402-544.

DEFENSOR DEL PUEBLO DE LA NACIÓN 2007. Informe especial cuenca del rio Reconquista. Primera parte. Buenos Aires: Defensoría de la Nación.

DE LA TORRE, Fernando, FERRARI, Lucrecia, y SALIBIÁN, Alfredo. Long-term in situ toxicity bioassays of the Reconquista River (Argentina) water with Cyprinus carpio as sentinel organism. Water, Air and Soil Pollution. 2000, 121(1-4), 205-215. DOI 10.1023/A:1005243521758. ISSN 1573-2932.

D’HERS, Victoria. Asentamientos sobre basurales a cielo abierto. Explotación, segregación y expulsión en el manejo de los residuos. Revista Desarrollo Local Sostenible. 2013, 6(16). ISSN 1988-5245

FEDEROVISKY, Sergio. Informe sobre la contaminación del Rio Reconquista. Buenos Aires: Greenpeace Argentina, 1988.

FERNÁNDEZ, Leonardo y HERRERO, Ana Carolina. Infraestructura de servicio de agua y cloacas, demanda y preservación del recurso hídrico subterráneo. El caso de la Región Metropolitana de Buenos Aires. En Di Pace, María y Barsky, Andrés. Agua y Territorio. Fragmentación y complejidad en la gestión del recurso hídrico en la Región Metropolitana de Buenos Aires. Buenos Aires: Fundación CICCUS; Los Polvorines: Universidad Nacional de General Sarmiento, 2012.

HERRERO, Ana Carolina y FERNÁNDEZ, Leonardo. De los ríos no me río: diagnóstico y reflexiones sobre las Cuencas Metropolitanas. Buenos Aires: Temas Grupo Editorial, 2008. ISBN 978-950-9445-53-6.

INSTITUTO NACIONAL DE ESTADÍSTICA Y CENSOS 2013. Censo Nacional de Población, Hogares y Viviendas 2010 / REDATAM+SP. Buenos Aires: INDEC.

KUCZYNSKI, David. El Reconquista. Cronología de un río cercano. Buenos Aires: Letrabuena, 1993.

MINISTERIO DE ASUNTOS AGRARIOS DE LA PROVINCIA DE BUENOS AIRES 1984. Las secas y las inundaciones en la Provincia de Buenos Aires. Obras de retención y no de desagüe. La Plata: Gobierno de la Provincia de Buenos Aires.

MINISTERIO DE ECONOMÍA DE LA PROVINCIA DE BUENOS AIRES 1985. Cuenca inundable Río Reconquista. Datos básicos. La Plata: Gobierno de la Provincia de Buenos Aires.

MINISTERIO DE OBRAS PÚBLICAS DE LA PROVINCIA DE BUENOS AIRES 1964. Estudio Hidrológico del Río Reconquista. La Plata: Gobierno de la Provincia de Buenos Aires.

ORDENANZA 742. Municipalidad de Tigre. 1972.

PERALTA, Verónica. La rectificación del río Reconquista y el barrio Obligado: Proyectos y procesos. En Charrière, Margarita. Costas y cuencas de la Región Metropolitana de Buenos Aires: estudios, planes y proyectos. Buenos Aires: Consejo Profesional de Arquitectura y Urbanismo, 2017, pp. 133.

PINTOS, Patricia. Las opacidades del urbanismo privado y el rol del Estado. Elementos para la reflexión en la producción de megaurbanizaciones cerradas en la cuenca baja del río Luján, RMBA. En Actas del XV Encuentro de Latinoamericanistas Españoles, Madrid, 2012.

PORTO, Mónica y PORTO, Rubem. Gestão de bacias hidrográficas. Estudos Avançados. 2008, 22(63), 43-60. DOI 10.1590/S0103-40142008000200004. ISSN 0103-4014.

POTOCKO, Alejandra. Transformaciones de un territorio de borde. La cuenca del río Reconquista en el ámbito metropolitano de Buenos Aires. En Del conocimiento al desarrollo. Nuevos desafíos de la Universidad en la gestión del desarrollo urbano contemporáneo. Segunda parte, Escalas, Buenos Aires, 26-28 de octubre de 2016. Buenos Aires: Eudeba. Pp. 172-181. ISBN 978-950-23-2651-1.

POTOCKO, Alejandra. Cartografías intencionadas de un territorio fluvial. Representaciones e interpretaciones del río Reconquista y su transformación. En Primeras Jornadas de investigación "Ríos Urbanos: nuevas 
perspectivas para el estudio, diseño y gestión de los territorios fluviales". Buenos Aires, 2-3 de noviembre de 2017. Universidad Nacional de La Plata / Universidad Nacional de San Martín.

POTOCKO, Alejandra. Las cuencas como bordes. Palabras, nociones y procesos para una lectura del Área Metropolitana de Buenos Aires. Anales del IAA. 2017, 47(2), 239-249. ISSN 2362-2024.

PUGLIESE, Luciano y SGROI, Alejandra. El papel de la administración en la aprobación de las urbanizaciones cerradas en humedales: una institucionalidad borrosa. Análisis del marco legal y normativo. En Pintos, Patricia y Narodowski, Patricio. La privatopía sacrílega. Efectos del urbanismo privado en humedales de la cuenca baja del río Luján. Buenos Aires: Imago Mundi, 2012, 123-163.

RAUSCH, Gisela Ariana. Estado, Desarrollo y Naturaleza: el caso del proyecto Paraná Medio bajo el paradigma hidráulico nacional (Argentina, 1958-1986). Estudios Socioterritoriales. 2016, vol. 20, DOI 10.1590/S1414753X2012000200010. ISSN 1809-4422.

RíOS, Diego. Planificación urbana privada y desastres de inundación: las urbanizaciones cerradas polderizadas en el municipio de Tigre, Buenos Aires. Economía, Sociedad y Territorio. 2005, V(27), 63-83. ISSN 1405-8421.

RíOS, Diego. Producción de espacio de riesgo de desastres a partir de la urbanización de áreas inundables. Los bañados de Tigre, su historia y sus transformaciones recientes. Tesis de doctorado en Geografía, Universidad de Buenos Aires, 2010.

RÍOS, Diego y PÍREZ, Pedro. Urbanizaciones cerradas en áreas inundables del municipio de Tigre: ¿producción de espacio urbano de alta calidad ambiental? EURE. 2008, XXXIV(101), 99-119. ISSN 0250-7161.

SADAÑIOWSKI, Ivana. El problema de las inundaciones en la cuenca del río Reconquista: la represa Ingeniero Carlos F. Roggero, y las funciones ecológicas. Tesis de grado en Ecología Urbana, Universidad Nacional de General Sarmiento. 2003.

SANTILLAN, Laura. Prácticas cotidianas e intersecciones entre la Iglesia Católica y grupos familiares en asentamientos populares del Gran Buenos Aires. Cuadernos de Campo. 2008, 17(17), 111-132. DOI 10.11606/issn.2316-9133.v17i17p111-132. ISSN 2316-9133.

SEGURA, Ramiro. Segregación residencial, fronteras urbanas y movilidad territorial. Un acercamiento etnográfico. Cuadernos del IDES. 2006, 9, 3-24. ISSN 1668-1053.

SUÁREZ, Francisco y LOMBARDO, Rubén. Amenaza, vulnerabilidad social y riesgo en las aguas del Delta. La construcción de la demanda social. En Di Pace, María y Barsky, Andrés. Agua y territorio. Fragmentación y complejidad en la gestión del recurso hídrico en la Región Metropolitana de Buenos Aires. Los Polvorines: Universidad Nacional de General Sarmiento; Buenos Aires: Fundación CICCUS, 2012, pp. 259-292.

TORRES, Horacio. El mapa social de Buenos Aires. 1940-1990. Buenos Aires: Secretaría de Investigación y Posgrado. Facultad de Arquitectura, Diseño y Urbanismo, Universidad de Buenos Aires, 1993.

VAPÑARSKY, César. La Aglomeración Gran Buenos Aires. Expansión espacial y crecimiento demográfico entre 1869 y 1991. Buenos Aires: Eudeba, 2000. ISBN 950-23-1022-5.

WILLIAMS, Fernando. Los ríos de Buenos Aires: una perspectiva histórica. En Charrière, Margarita. Costas y cuencas de la Región Metropolitana de Buenos Aires: estudios, planes y proyectos. Buenos Aires: Consejo Profesional de Arquitectura y Urbanismo, 2017, pp. 16-23.

WILLIAMS, Fernando, GARAY, Diego y POTOCKO, Alejandra. Paisaje, ambiente y forma urbana en la cuenca del río Reconquista. El proyecto "Ríos Urbanos" como plataforma de abordaje. Arquisur Revista. 2017, 12, pp. 126139. ISNN 2250-4206. 